\title{
A FIRST ATTEMPT TO DEFINE LEVEL OF DETAILS BASED ON DECISION-MAKING TASKS: APPLICATION TO UNDERGROUND UTILITY NETWORK
}

\author{
Z. Chen ${ }^{1 *}$, J. Pouliot ${ }^{1}$, F. Hubert ${ }^{1}$ \\ ${ }^{1}$ Department of Geomatics Sciences, Université Laval, Québec, Canada \\ zihan.chen.1@ulaval.ca; (jacynthe.pouliot, frederic.hubert)@ scg.ulaval.ca
}

KEY WORDS: 3D modeling, level of detail, multiple representations, underground utility network, network maintenance, decisionmaking.

\begin{abstract}
:
Level of detail (LoD) is a key concept for 3D city modeling to optimise visualisation. The LoDs of CityGML shows this trend. This paper explores the relevance of having LoD for visualising 3D model of Underground Utility Networks (UUN). A new approach is proposed for designing multiple LoDs modeling in creating an explicit link between the content of the 3D model and the decisionmaking process (or operational tasks) to be performed by a user. This Multiple Level of detail Approach (MLA) is divided into four steps. The first step requires defining the visualisation needs in terms of five variables (geometry, topology, semantic, contextual information, and semiology). Next, tasks to be performed are analyzed and categorized. Finally, a matrix of possible LoDs is created for all tasks and the minimum LoD required is proposed. In this paper, we applied this approach for the use case of granting connection permits to water and sewer networks. Learning aspects are proposed in the discussion.
\end{abstract}

\section{INTRODUCTION}

\subsection{Context}

Cartographic representation, like maps or three dimensional (3D) models, allows the visualisation of geographic features at various scales with conventional rules of semiotic (MacEachren, 2004; Wang, 2015). Varying map scale or cartographic generalization are key concepts in 2D to improve visualisation and conveys spatial information suitably. In 3D model visualisation, the same requirements of varying the level of information to be modeled and displayed exist.

\subsection{The concept of level of detail}

In 3D modelling, a large consensus exists in the geographic modeling domain for varying scales when visualising, mostly supported by the development of CityGML and Building Information Model (BIM), and it refers to the concept of Level of Detail (LoD). For instance, in city modeling, the concept of LoD receives a lot of attention, and CityGML is a clear example of this tendency (Biljecki et al., 2014; Gröger et al., 2012; Kolbe, 2009). The concept of LoD or the capability to describe the same reality with distinct and multiple levels of abstraction is largely recognized as required to support the execution of visual tasks like being able to identify, distinguish or select a specific object in the field of view (Fan and Meng, 2012; Forberg, 2007; Forberg and Mayer, 2006; Glander and Döllner, 2009; Kada, 2006; Mao et al., 2011; Thiemann, 2002). Meng and Forberg (2007) define $\mathrm{LoD}$ as a uniform number of milestones along with the scalespace when taking the scale-space as a linear continuum. Biljecki et al.(2014) redefine LoD as the degree of its adherence to its corresponding subset of reality. In CityGML, the LoD concept is different from computer graphics models as the latter one is continuous and aiming at efficient visualisation (Gröger et al., 2012). Besides, spatial data producers are using various techniques to map real-world features under different data quality regulations and towards diverse end-users (Vangenot et al., 2002). The same entity can be created and modeled repeatedly but contains different semantic meanings, abstracted as different geometric primitives and shown as multiple graphic representations (Bédard et al., 2007).

Consequently, the concept of $\mathrm{LoD}$ is helpful to decrease the size of 3D models, satisfy the demand in different phases such as data acquisition, modeling, visualisation and analysis, and combine semantic meanings with cartographic and geometric elements.

\subsection{Research Objectives}

Based on the development and application of LoD, it could be concluded that LoD is a valuable concept to be integrated into the process of $3 \mathrm{D}$ modeling. However, as stated by Biljecki et al.(2014), it is considered that the definition of LoD is still vague and in most cases, it is arbitrarily delineated and numbered. Furthermore, as it will be discussed later, the application of LoD to underground utility networks, that are not visible objects and having specific characteristics, is still not enough developed and needs advancing investigation.

In this research, a hypothesis is made that the definition of LoD should be enabled in having in target specific group of decisions or tasks to perform. To test this hypothesis, an approach called the Multiple Level of detail Approach (MLA) is defined. It states a set of key variables: geometry, topology, semantics, contextual information and semiology, from which various LoD can be derived. Next, MLA brings a list of tasks into the equation that are put in perspective with the five key variables. The first attempt presented in the paper is about 3D visual tasks required in the context of Underground Utility Network (UUN) operation. Then, MLA creates a matrix of possible LoDs and identifies the minimum required one to achieve the task.

The main innovative aspect of this paper is to appraise the definition of LoD based on the achievement of categories of decision-making tasks. The application of LoD to UUN is also original since the literature review illustrated that there are very few proposals and concrete application. The following sections first reviews LoD concept in building modelign and UUN modeling, then present the multiple levels of detail approach and 
next its application to water supply maintenance tasks. At last, this paper reaches to a conclusion with a discussion and further work.

\section{MULTIPLE LEVEL OF DETAIL REASONING}

If we go back and examine how the LoD was defined in a multiscale representation appliance, we can identify interesting learning aspects. The following discussion is proposed for building and underground utility network modeling.

\subsection{LoD and city building modeling}

For building modeling, CityGML can represent four different aspects of virtual 3D city models: semantics, geometry, topology, and appearance in five discrete levels (LoD0 to LoD4 with increasing accuracy and structural complexity) (Kolbe, 2009). Different LoDs often arise from independent data collection processes and benefit from visualisation and analysis. LoD0 is essentially a two and a half dimension (2.5D) digital terrain model (DTM). LoD1 is a block model without roof structures, LoD2 has distinctive roof structures, LoD3 is a model with detailed walls and roof, doors, windows, and bays; and LoD4 adds interior structures (Kolbe, 2009) (Figure 1).

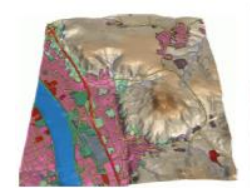

LoD0

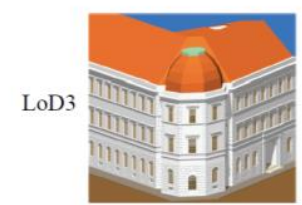

LoD1

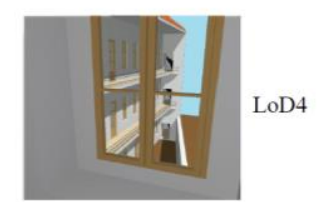

Figure 1. LoD concept illustration by CityGML (Kolbe, 2009).

The definitions of five LoDs are based on different application requirements and demands to reflect independent data collection processes (Gröger et al., 2012). The definitions of the five LoDs refer to all thematic features of CityGML. Each LoD should reflect specific application requirements and be suitable for a certain class of applications. In these levels, the geometry should be similar to spatial objects' original geometry and the representation of their detail should depend on visibility. LoD can represent model scale: from regional, city, district, to architectural models. By naming the LoD of a dataset, people can indicate a clear idea about data granularity and the complexity of the 3D city model dataset (Coors and Flick, 1998; Köninger and Bartel, 1998). However, the definition of CityGML LoD is not precise and clear enough to state the requirements and specification of each level, and the definition of one LoD seems to be arbitrary without connections (Biljecki et al., 2014). Thus, Biljecki (2014) defines LoD of a 3D city model as the degree of its adherence to its corresponding subset of reality. Six LoDdefining parameters, list of features, their geometric complexity, dimensionality, appearance, spatio-semantic coherence, and attributes, are proposed allowing users to define their own series of LoDs.

In the field of Building Information Modeling (BIM), a similar concept as Level of Development (LoDev) is forwarded to Industry Foundation Class (IFC), which concerns more about increasingly detailed design for different planning stages. It defines various development stages of a construction project in BIM, from LoDev 100, 200, 300, 400, and 500 (BIM Forum, 2019). Different planning stage involves with different level of certainty about an object. LoDev 100 is the beginning of a building project with conceptual design. LoDev200 uses approximate geometry for buildings as schematic design. LoDev300 is a detailed design with precise construction documents. LoDev400 is suitable for fabrication and assembly fabrication. LoDev500 is the post-construction as-built stage of a project. Different levels of building models will be generated ranges over non-geometric presentations, most primitive, approximate geometry, precise geometry (containing the accurate quantity, size, location, and systematic relationships), a detailed model suitable for fabrication and assembly fabrication of represented components.

In summary, for 3D building modeling, the definition of LoD or LoDev is laying open to data availability, application domain (such as bridges, tunnels, indoor navigation), geometry complexity, individual objects/subobjects, structures, and/or classes selection.

\subsection{LoD and underground utility network modeling}

It is now interesting to survey the application of LoD in a domain that presents distinct characteristics compared with buildings. Underground Utility Networks (UUN) such as water supply and sewage pipelines or communication cables are the "lifelines" of an urban system, and they all face challenges for detecting, mapping, and managing (Daems, 2017; Lieberman and Ryan, 2017). Modeling in 3D UUN is a major trend and it should be able to provide multiple representations considering data accessibility and model comprehensibility (American Society of Civil Engineers, 2002; Van Son et al., 2018). There are a few studies about defining LoD of underground facilities with varieties and numbering. The construction planning of UUN relies heavily on the use of different scales for representing geometric information on a suitable level of detail.

For instance, as illustrated in Figure 2, BIM Forum and the American Institute of Architects have defined the geometric elements and contained information on some piping and equipment such as air supply, water, sewerage, and fuel.

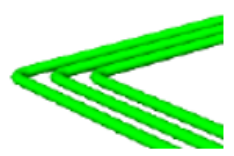

LODev-200 Domestic Water Pipe

(Schematic layout with approx. size, shape, and location)

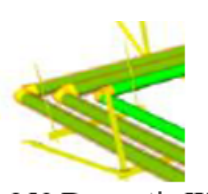

LODev-350 Domestic Water Pipe

(Modeled as actual elements size, shape, and location)
Figure 2. LoDev of water piping extracted from BIM Forum, 2019, p.132-133.

Figure 3 shows an example of LoDs extracted from Breunig et al. (2011) designed for subways. The representations on the diverse LoDs result from different detailing demands in the individual planning stages. In this definition of levels, it mostly considered corresponding geometrical representation on each LoD. The geometry transferring models from finer LoDs to coarser ones: 2D polyline, 2D polyline with width, 3D tunnel geometry, precise 3D geometry with inner shell, and precise 3D geometry with more components. Topological consistency of the models is preserved. This application could facilitate planning processes for the subway track. 


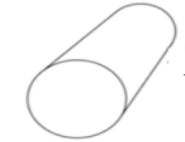

Level 3
3D Tunnel geometry

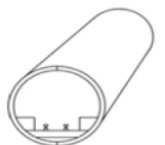

Level 5

Precise 3D geometry incl. rails/traffic, inner shell

Figure 3. LoDs for subway tunnels extracted from Breunig et al., 2011 .

Figure 4 extracted from Borrmann et al., (2013) shows IFC-based tunnel modeling for different construction planning stages from modeling outer shell to modeling interior.
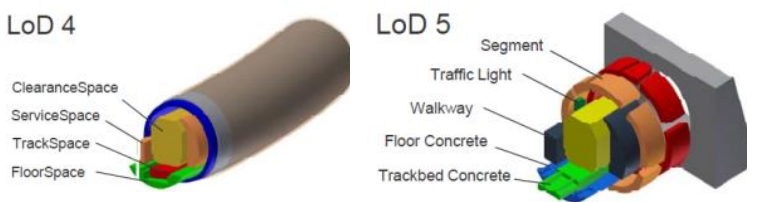

Figure 4. LoDs of tunnel extracted from Borrmann et al., 2013, p.80.

Finally, Figure 5 extracted from Gröger et al. (2012) illustrates LoDs created to represent either different tubes of a tunnel or different sections. In this LoD, the tunnel volume is represented by different geometry, and can also be differentiated semantically by boundary surfaces.

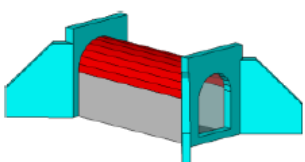

LoD 2

3D Tunnel with surface, value, terrain, outer installation

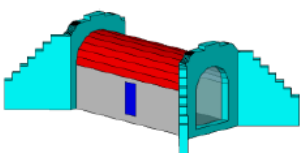

LoD 4

3D tunnel same as LoD + openings, and interior

Figure 5. LoDs of tunnels extracted from Gröger et al., 2012, p. 86.

Other attempts of creating LoD are either targeted at one specific facility (subway, tunnels, etc.) or pre-defined application (for planning and construction process). It leads to a situation that researchers involved in creating multiple representations and enhancing visualisation appearance of UUN are somehow not consistent, question of why this LoD and not another remains to be answered, various levels are arbitrary defined, and semiology and semantic aspects are loosely coupled. There is no real converging solution that contribute to interoperability and thus limits the usage and integration of LoD in day-to-day operation.

\section{MULTIPLE LEVELS OF DETAIL APPROACH}

In this paper, we take the definition of LoD from Meng \& Forberg (2007) as a uniform number of milestones along with the scalespace when taking the scale-space as a linear continuum. This implies defining scale space and a continuum (i.e., LoD has to be ordered). We also have in mind the possibility to change automatically from one LoD to another.

To enable the creation of multiple LoDs, the MLA is proposed and it is divided into four steps. Figure 6 illustrates the steps and the next sections explain how it works.

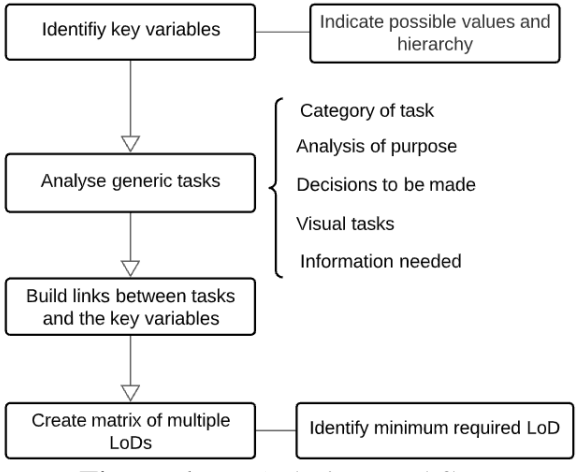

Figure 6. MLA design workflow

\subsection{Key variables in 3D modeling process}

To model 3D features with multiple levels of representations, a variety of information (called key variables) has to be taken into account. These variables are indispensable or atomical to be taken into consideration when modeling $3 \mathrm{D}$ city objects. Table 1 shows the list of selected variables.

As it is done in 3D Geographic Information System (GIS) and 3D City model, LoD is mostly applied to describe the complexity of the geometry and semantic differentiation (Kolbe, 2009), and it is of great value in effective visualisation and analysis. Therefore, geometry and semantics are selected as two variables. Likewise, since there are increasing requirements in topology for 3D GIS (Ellul and Haklay, 2006), topology is chosen as a variable to distinguish. Meanwhile, and since UUN are not visible from the surface, contextual data are considered as required (Chen et al., 2010). Graphic multiplicity also leads to taking graphic as a variable for Multi-LoD: the same cartographic element is represented by different visual variables following different semiology rules (Bedard and Bernier, 2002). Contextual information is another aspect to facilitate and achieve the visual goal. Moreover, sometimes, not all these variables will be used when modeling spatial objects other than UUN and sometimes additional variables might be needed to depict further needs.

\begin{tabular}{|l|l|}
\hline Variables & Explanation \\
\hline Geometry & Dimension of the space (number of axes) \\
\cline { 2 - 2 } & Dimension of the geometric primitive \\
\hline Topology & Inner topology. \\
\cline { 2 - 2 } & Spatial relationship \\
\hline Semantics & $\begin{array}{l}\text { Definition of the class of objects (name of } \\
\text { specific components) }\end{array}$ \\
\cline { 2 - 2 } & $\begin{array}{l}\text { Description of objects (attributes and domain of } \\
\text { values) }\end{array}$ \\
\hline $\begin{array}{l}\text { Contextual } \\
\text { information }\end{array}$ & $\begin{array}{l}\text { Presence or absence of additional information, } \\
\text { such as vegetation, roads, ground information, } \\
\text { etc. }\end{array}$ \\
\hline Semiology & $\begin{array}{l}\text { Presence or absence of multiple sets of symbols } \\
\text { in color, shape, size, texture, transparency, and } \\
\text { other cartographic expressions. }\end{array}$ \\
\hline
\end{tabular}

Table 1. List of key variables to describe 3D model.

\subsection{Task analysis}

After choosing suitable variable categories and values, the decision-making process is analyzed to infer the results of a use case, and spatial operations are depicted. Data process and visual task for each decision-making step are explained. Then the required information of each variable in order to produce $3 \mathrm{D}$ models is discussed. 
To analyze the use case, the purpose and main working process are the first to be determined. Then, the decision to be made needs to be identified. In this firt attempt, decisions related to 3D visual tasks are chosen. These decisions could be answered by "yes" or "no"; or could be reached with the assistance of advanced information. Data model which indicates the input data or existing data for users to accomplish the tasks is to be provided as well. Visual tasks are those that require to view the spatial representation and with this visual representation, certain results (i.e. count the window number in a 3D building model) or visual actions such as zoom in, zoom out, navigation can be conducted.

To fulfill the visual tasks, the information needed for each variable is listed, and then connections between LoD and tasks is made in the next step. Based on the information needed for the tasks, the variables involved in and their granularity, the tasks can be categorized in the same group, and in other words, they will need the same LoD to be conducted. This specific LoD will be able to solve this category of visual tasks. Thus, the decisionmaking process and LoD can be linked.

For visualisation tasks of UUN, Wang et al.,(2019) states that there are three aspects for 3D visualisation including component, condition, and inspection. Not only the visualisation of utility geometric shape but also the visualisation of condition information for both the individual component and the whole network are to be visualized. Components visualisation means each utility component and the detailed utility parts consisting the components can be presented. Conditions of utility can be visualized in different colors. Inspection visualisation can realized by the representation of terrain situation, surrounding buildings, and other infrastructures.

\subsection{Define multiple LoDs}

Subsequently, LoD is designed for each category of visual tasks and variables. For now, by having a sequence of 0 (absent) and 1 (present) for the five key variables (except for the geometry), the LoD is numbered. For geometry, the dimension of the geometric primitive $(\mathrm{GM})$ and the dimension of space $(2=2 \mathrm{D}$ or $3=3 \mathrm{D})$ are required. For GM dimension, the higher dimension of the geometric primitives $(\mathrm{GM})$ is used as $(0=0 \mathrm{D}, 1=0 \mathrm{D} / 1 \mathrm{D}, 2=$ $0 \mathrm{D} / 1 \mathrm{D} / 2 \mathrm{D}, 3=0 \mathrm{D} / 1 \mathrm{D} / 2 \mathrm{D} / 3 \mathrm{D})$. It goes like this as examples:

- LoD 22-00-10-01: space 2D, GM 2D, no connection, no spatial relationships, definition, no attribute, no contextual data, semiology.

- LoD 32-00-11-00: space 3D, GM 2D, no connection, no spatial relationships, definition, attribute, no contextual data, no semiology.

- LoD 33-00-11-00: space 3D, GM 3D, no connection, no spatial relationships, definition, attribute, no contextual data, no semiology.

For the other steps of creating multiple LoD matrix and identify the minimum required LoD, since it has to be linked to the task, the explanation is presented in the next section with a use case.

\section{APPLICATION TO UNDERGROUND UTILITY NETWORK}

\subsection{Context of Underground Utility Network Management and Maintenance}

Due to the pressure of above-surface land insufficiency, many countries and cities have cast their sight on the field of developing underground facilities (Schrotter and Van Son, 2018).
While lacking proper UUN information and representation could cause stalled, delay, increasing costs, and risk, as well as poor UUN management, could lead to serious consequences threatening people's safety and property. Therefore, a reliable visualisation and $3 \mathrm{D}$ model is needed to guide the utility location, urban planning and land administration process (Ghodsvali, 2018; Yan et al., 2019). Furthermore, for different application tasks and various needs of decision-makers, the UUN model should be able to provide multiple representations considering data accessibility and model comprehensibility. Detailed information should be adaptively simplified and chosen, in order to optimize the visualisation-complexity, computational efficiency and enriches expressions. In this paper, the water supply pipe network management and maintenance is chosen as the purpose of decision-making.

The whole aim is to provide an adequate and reliable supply of safe water. Maintenance involves activities that keep the system in good operating condition (van Zyl, 2014). Common operation and maintenance tasks contain locating pipes, locating leaks, repairing leaking pipes, flushing, reservoir cleaning, disinfection, checking pump operation, common pump problems, pressure management, etc (van Zyl, 2014). Relevant operational goals include maps control and updating, leak detection and repair, cross-connection control and backflow prevention, exercising of valves, water main repair or replacement (Mays, 2018).

\subsection{Use Case description}

In this paper, according to the needs of municipality, granting connection permits to water and sewer networks is selected as a real use case. This use case presents the main tasks of a city employee responsible for issuing permits for connection to sewer and water systems. After receiving the request, information of underground infrastructure in a certain place must be obtained in order to determine whether or not a permit can be granted to the applicant. Data model for this use case is shown in Figure 7.

The main process of this use case is to locate the involved address or parcel of land (lot) and extract information of existing infrastructure. This use case involves the following steps:

1. Locate the request of making a new connection

i. Find the location according to the lot number

ii. Find the location by address

2. Obtain information on the pipes and elements of the water or sewer network

i. Obtain duct flow

ii. Obtain the duct material

iii. Obtain the installation date

iv. Obtain the model and type of conduit

v. Obtain information on the owner of the conduit

vi. Obtain the number of existing connections on the conduit

3. Locate the conduits in relation to their environment

i. View the conduits on different base maps as needed in order to locate them as best as possible in relation to their environment by having, for example, either the street names or a satellite image

ii. Estimate distances between conduits and different contextual elements such as buildings and streets

4. Obtain additional information on the affected lot

i. Combine engineering plans and/ or certificates of location

ii. Obtain information on the owner of the lot

iii. Consult environmental or drainage study documents 


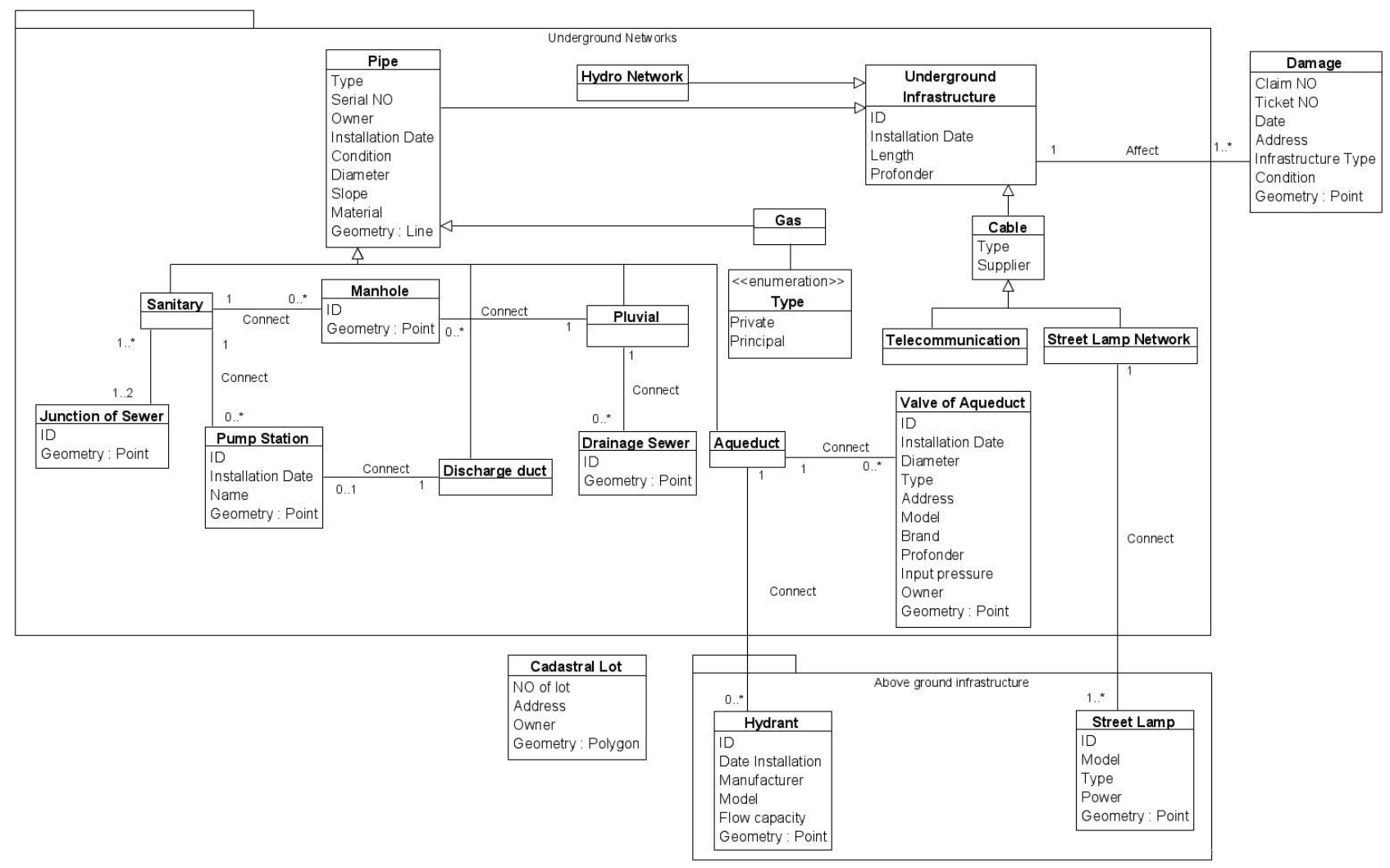

Figure 7. Data model of Underground Utility Network.

\subsection{Application of MLA to UUN}

For UUN, key variables have more specific meaning and indications. Possible values for these variables need to contain more information. For topology, the UUN should also discuss the connectivity and spatial relationship particular with networks (intersections, superimpose, etc.). For semantics, the components of network are taken into consideration. For contextual information, buildings could become supplemental one.

Based on the MLA approach and the analysis of the decisionmaking process, the following task analysis can be obtained:

1. Purpose: Management of municipal assets for underground infrastructures.

2. Decision to be made: Whether a connection request for water or sewer network can be granted.

3. Visual tasks involved:

i. Locate request and see the distribution of potential pipe to connect with.

ii. View the distribution of pipe along with its environment. iii. See the existing connections of certain segments of pipe networks and count the number.

iv. See the depth distribution of pipes and appreciate the vertical position between surface objects (street and buildings).

v. Identify and view buildings/land parcels overlapping a request location.

Three visual tasks are chosen as illustrations of variables and LoD Matrix. Visual task 1 is to locate a new connection request and see the distribution of potential pipe to connect. Visual task 2 is to see existing connections of certain segments of pipe networks and count the number. Visual task 3 is to view the depth distribution of pipes and appreciate the vertical position between surface objects (streets and buildings). For each task, the minimumal information needed to do this task linked with key variables is provided and converted to the LoD numbering structure following the rules in section 3.3. The third columns of the following tables (Table 2, 3 and 4) illustrate possible LoDs to do this visual task and the minimum LoD requested (in red) to achieve this decision. It has to be mentioned that more than one LoD would be possible to accomplish the task, but for now, the target was to identify the minimum required level. Figures 8,9 , 10 and 11 illustrates those minimum or possible LoDs illustration for the same area.

\begin{tabular}{|c|c|c|c|}
\hline \multicolumn{2}{|c|}{ Key variables } & $\begin{array}{c}\text { Information } \\
\text { needed }\end{array}$ & $\begin{array}{l}\text { Possible } \\
\text { LoDs }\end{array}$ \\
\hline \multirow[b]{2}{*}{ Geometry } & $\begin{array}{l}\text { Dimension } \\
\text { of the space }\end{array}$ & 2D space & \multirow{8}{*}{$\begin{array}{c}21-00-10-10 \\
\text { (Figure 8) } \\
21-00-10-11 \\
21-00-11-10 \\
21-00-11-11 \\
21-01-10-10 \\
21-01-10-11 \\
21-01-11-10 \\
21-01-11-11 \\
21-10-10-10 \\
21-10-10-11 \\
\ldots \\
\text { (higher LoD } \\
\text { are also } \\
\text { possible) }\end{array}$} \\
\hline & $\begin{array}{l}\text { Dimension } \\
\text { of the GM }\end{array}$ & 1D GM & \\
\hline \multirow{2}{*}{ Topology } & $\begin{array}{c}\text { Connectivity } \\
\text { or not }\end{array}$ & No. & \\
\hline & $\begin{array}{c}\text { Spatial } \\
\text { relationships }\end{array}$ & No. & \\
\hline \multirow[t]{2}{*}{ Semantic } & $\begin{array}{c}\text { Definition of } \\
\text { the class of } \\
\text { objects }\end{array}$ & Pipe definition. & \\
\hline & $\begin{array}{l}\text { Description } \\
\text { of objects }\end{array}$ & No. & \\
\hline \multicolumn{2}{|c|}{ Contextual } & Yes. & \\
\hline \multicolumn{2}{|c|}{ Semiology } & No & \\
\hline
\end{tabular}

Table 2. Visual task 1: Locate request and see the distribution of potential pipe to connect with. 


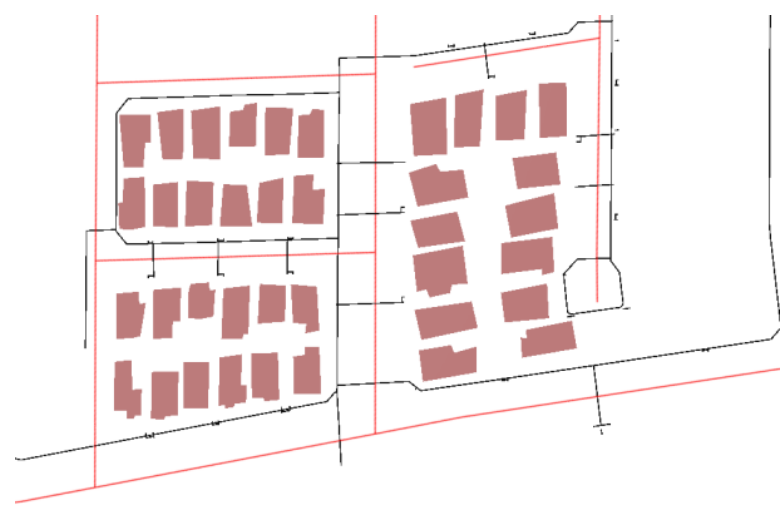

Figure 8. LoD 21-00-10-10.

LoD 21-00-10-10 is selected as the minimum LoD to fulfill the task of locating a pipe and the distribution of them. Because at least 1D GM (line geometry) in 2D space is needed; topology is not necessary to solve this task, and for semantics, what kind of pipe is laying here is needed to know. Lot information or building address information to perform the location query is wanted. Semiology is not necessary.

\begin{tabular}{|c|c|c|c|}
\hline \multicolumn{2}{|c|}{ Key variables } & $\begin{array}{l}\text { Information } \\
\text { needed }\end{array}$ & $\begin{array}{l}\text { Possible } \\
\text { LoDs }\end{array}$ \\
\hline \multirow{2}{*}{ Geometry } & $\begin{array}{l}\text { Dimension } \\
\text { of the space }\end{array}$ & 3D space & \multirow{8}{*}{$\begin{array}{c}32-11-10-00 \\
\text { (Figure 9) } \\
32-11-10-10 \\
32-11-10-11 \\
32-11-10-01 \\
32-11-11-00 \\
32-11-11-01 \\
32-11-11-10 \\
32-11-11-11 \\
33-11-10-00 \\
33-11-10-01 \\
33-11-10-10 \\
33-11-10-11\end{array}$} \\
\hline & $\begin{array}{l}\text { Dimension } \\
\text { of the GM }\end{array}$ & 2D GM & \\
\hline \multirow{2}{*}{ Topology } & $\begin{array}{c}\text { Connectivity } \\
\text { or not }\end{array}$ & Connectivity & \\
\hline & $\begin{array}{c}\text { Spatial } \\
\text { relationships. }\end{array}$ & $\begin{array}{l}\text { Intersection, } \\
\text { overlapping }\end{array}$ & \\
\hline \multirow[t]{2}{*}{ Semantic } & $\begin{array}{c}\text { Definition of } \\
\text { the class of } \\
\text { objects }\end{array}$ & $\begin{array}{l}\text { Component } \\
\text { definition. }\end{array}$ & \\
\hline & $\begin{array}{l}\text { Description } \\
\text { of objects }\end{array}$ & No. & \\
\hline \multicolumn{2}{|c|}{ Contextual } & No. & \\
\hline \multicolumn{2}{|c|}{ Semiology } & No & \\
\hline
\end{tabular}

Table 3. Visual task 2: See the existing connections of certain segments of pipe networks and count the number.

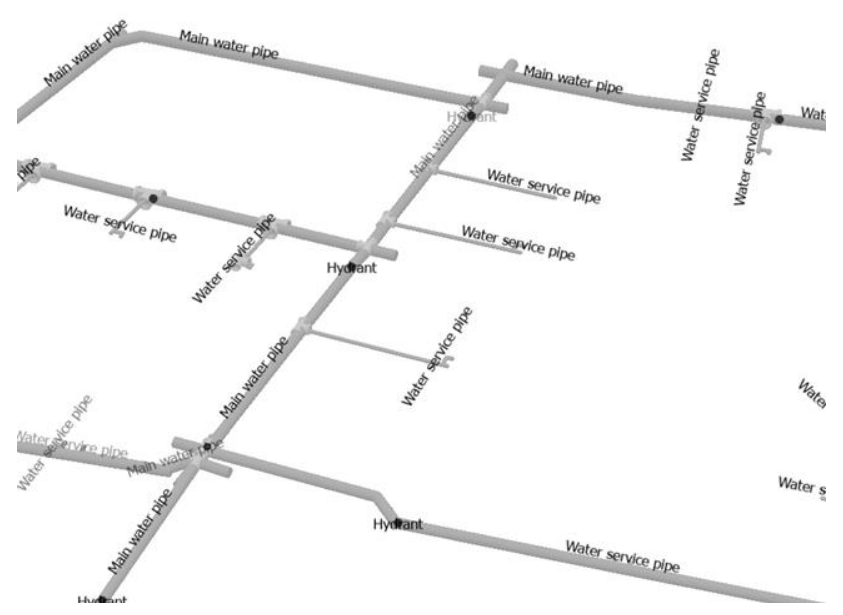

Figure 9. LoD 32-11-10-10.
For visual task 2, in order to see the existing connections and be able to count its quantity, the visualisation has to be carried out in 3D space, because of vertical superposition and occlusion. Since it could have 2D shape to present 3D object, at least 2D GM will be needed. Connectivity is needed to be shown. Spatial relationship and the view of correct connection is shown. Fitting and other components need to be shown and identified. Specific values of pipes are not needed, contextual information is not necessary because this task is only about the pipe itself. This is why LoD 32-11-10-00 is selected as the minimum required LoD.

\begin{tabular}{|c|c|c|c|}
\hline \multicolumn{2}{|c|}{ Key variables } & $\begin{array}{l}\text { Information } \\
\text { needed }\end{array}$ & $\begin{array}{l}\text { Possible } \\
\text { LoDs }\end{array}$ \\
\hline \multirow{2}{*}{ Geometry } & $\begin{array}{l}\text { Dimension } \\
\text { of the space }\end{array}$ & 3D space & \multirow{8}{*}{$\begin{array}{c}31-00-11-11 \\
\text { (Figures 10) } \\
31-01-11-11 \\
31-10-11-11 \\
31-11-11-11 \\
32-00-11-11 \\
32-10-11-11 \\
32-01-11-11 \\
32-11-11-11 \\
33-00-11-11 \\
\text { (Figure 11) } \\
33-01-11-11 \\
33-10-11-11 \\
33-11-11-11\end{array}$} \\
\hline & $\begin{array}{l}\text { Dimension } \\
\text { of the GM }\end{array}$ & 1D GM & \\
\hline \multirow[b]{2}{*}{ Topology } & $\begin{array}{c}\text { Connectivity } \\
\text { or not }\end{array}$ & No. & \\
\hline & $\begin{array}{c}\text { Spatial } \\
\text { relationships. }\end{array}$ & No & \\
\hline \multirow[t]{2}{*}{ Semantic } & $\begin{array}{c}\text { Definition of } \\
\text { the class of } \\
\text { objects }\end{array}$ & $\begin{array}{l}\text { Component } \\
\text { definition. }\end{array}$ & \\
\hline & $\begin{array}{c}\text { Description } \\
\text { of objects }\end{array}$ & Yes. & \\
\hline \multicolumn{2}{|c|}{ Contextual } & No. & \\
\hline \multicolumn{2}{|c|}{ Semiology } & No & \\
\hline
\end{tabular}

Table 4. Visual task 3: See the depth distribution of pipes and appreciate the vertical position between surface objects (street and buildings).

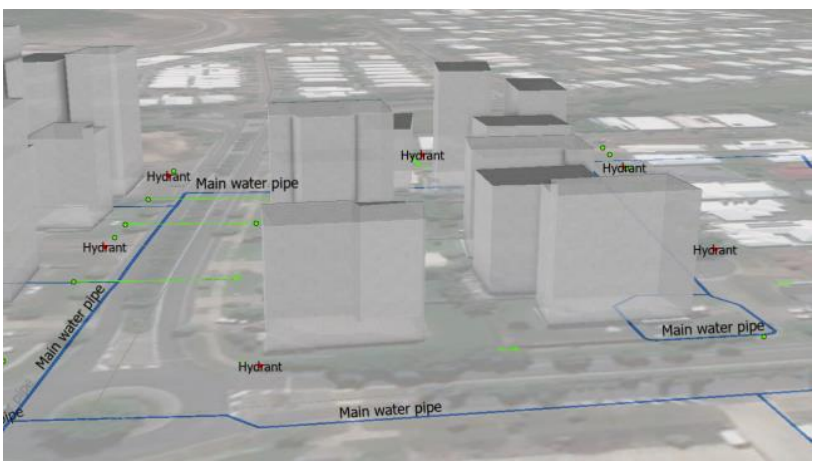

Figure 10. LoD 31-00-11-11.

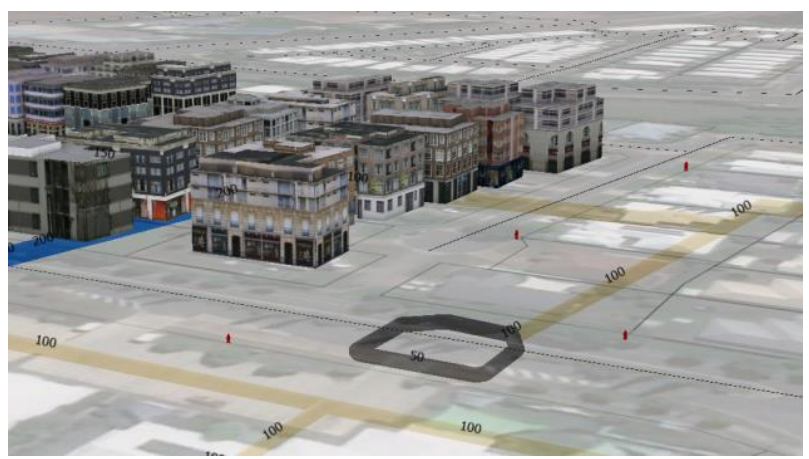

Figure 11. LoD 33-00-11-11.

For visual task 3, the third-dimensional space is needed in order to show the vertical overlay; the geometry representation could be $1 \mathrm{D}$ to $3 \mathrm{D} \mathrm{GM}$ for calculating the depth. Also, ground 
information, building information and street information will be needed to show the depth and get the vertical distance. Multiple transparencies to show the perspective relationships might be needed. This is why LoD 31-00-11-11 is selected as the minimum one.

\section{DISCUSSION AND FUTURE WORK}

This paper investigated the application of LoDs to underground utility network and for this purpose, a new manner is proposed to define LoD in linking the user's needs (or specific task to perform) and information required to enable the definition of those LoDs. Five variables (geometry, topology, semantic, contextual information, and semiology) are used to state the information required, for which, levels of detail are defined. The approach was applied to one specific use case.

The project is still in its phase of designing and validating but some learning aspects can be discussed. First, although the target was to create a hierarchy of LoDs, we were not able to achieve it fully. For instance, the semantics could be explored similarly as Bédard et al. (2007) and Bernier et al. (2008). In discussing with potential users, it is believed that there exist continuous and distinct levels and more exploration undertaken in that direction. Second, creating group of tasks in relation to LoD is still a challenge. For now, the selection of the minimum required LoD is done based on our own experience but in the coming period it will be validated with the help of UUN planners. We are examining adding more variables in the definition of the content of 3D modeling as data quality or time. Finally, the automation in producing multiple LoDs was not performed. The current 3D UUN LoD was produced manually based on the existing 2D dataset of UUN with varying 3D modeling techniques. As it is done for building modeling (Kelly et al., 2017), we are exploring the possibility of automatically producing different representations of the networks.

In overall, we are not able today to conclude in regards of the hypothesis we had about being able to define LoD based on specific group of decisions or tasks to perform. Neverthless, discussion with users of UUN are encouraging us to continue in this direction.

\section{ACKNOWLEDGEMENTS}

This work is funded by NSERC RGPIN-2015-05514 (JPouliot) and the author is supported by China Scholarship Council (CSC) Grant \#201904190003. The authors also would like to thank all reviewers for their comments and suggestions.

\section{REFERENCES}

American Society of Civil Engineers, 2002. Standard Guidelines for the Collection and Depiction of Existing Subsurface Utility Data. Reston, VA. doi.org/10.1061/9780784406458

Bedard, Y., Bernier, E., 2002. Supporting multiple representations with spatial databases views management and the concept of VUEL, in: Joint Workshop on Multi-Scale Representations of Spatial Data, ISPRS WG IV/3, ICA Com. on Map Generalization. Ottawa, Canada.

Bédard, Y., Bernier, E., Badard, T., 2007. Multiple representation spatial databases and the concept of Vuel, Encyclopaedia in Geoinformatics,. Idea Group Publishing, Hershey.

Bernier, E., Bédard, Y., Badard, T., Hubert, F., 2008. UMapIT@ (Unrestricted Mapping Interactive Tool): Merging the datacube paradigm with an occurrence-based approach to support ondemand web mapping, in: International Perspectives on Maps and the Internet. Springer, Berlin, Heidelberg, pp. 187-204.

Biljecki, F., Ledoux, H., Stoter, J., Zhao, J., 2014. Formalisation of the level of detail in 3D city modelling. Comput. Environ. Urban Syst. 48, 1-15.

Biljecki, F., Ledoux, H., Stoter, J., 2016. An improved LOD specification for 3D building models. Comput. Environ. Urban Syst. 59, 25-37.

BIM Forum, 2019. Level of development specification. Part I for building information models. bimforum.org/lod/.

Borrmann, A., Kolbe, T.H., Donaubauer, A., Steuer, H., Jubierre, J.R., 2013. Transferring multi-scale approaches from 3D city modeling to IFC-based tunnel modeling. ISPRS Ann. Photogramm. Remote Sens. Spat. Inf. Sci. 2, 75-85. doi.org/10.5194/isprsannals-II-2-W1-75-2013.

Breunig, M., Hinz, S., Menninghaus, M., Vögtle, T., Rank, E., Schilcher, M., Borrmann, A., Mundani, R.P., Ji, Y., Donaubauer, A., Steuer, H., 2011. Towards computer-aided collaborative subway track planning in multi-Scale 3D city and building models, in: Joint ISPRS Workshop on 3D City Modelling and Applications and the 6th 3D GeoInfo, 3DCMA 2011.

Breunig, M., Hinz, S., Menninghaus, M., Vögtle, T., Rank, E., Schilcher, M., Borrmann, A., Mundani, R.P., Ji, Y., Donaubauer, A., Steuer, H., 2011. Towards computer-aided collaborative subway track planning in multi-Scale 3D city and building models, in: Proceedings of the 6th 3D Geoinfo Conference.

Chen, J., Granier, X., Lin, N., Peng, Q., 2010. On-line visualisation of underground structures using context features, in: Proceedings of the 17th ACM Symposium on Virtual Reality Software and Technology - VRST '10. ACM Press, New York, USA, p. 167-170. doi.org/10.1145/1889863.1889898.

Coors, V., Flick, S., 1998. Integrating Levels of Detail in a WebBased 3D-GIS, in: Proceedings of the 6th ACM International Symposium on Advances in Geographic Information Systems, GIS '98. Association for Computing Machinery, New York, NY, USA, pp. 40-45.

Daems, J., 2017. Belgium, the Flanders region - an introduction to KLIP.

Ellul, C., Haklay, M., 2006. Requirements for Topology in 3D GIS. Trans. GIS 10(2), 157-175.

Fan, H., Meng, L., 2012. A three-step approach of simplifying 3D buildings modeled by cityGML. Int. J. Geogr. Inf. Sci. 26(6), 1091-1107.

Forberg, A., 2007. Generalization of 3D building data based on a scale-space approach. ISPRS J. Photogramm. Remote Sens. 62(2), 104-111. doi.org/10.1016/j.isprsjprs.2007.01.002.

Forberg, A., Mayer, H., 2006. Simplification of 3D building data. ZFV - Zeitschrift fur Geodasie, Geoinf. und Landmanagement 131(3), 148-152.

Ghodsvali, M., 2018. 3D Modelling of Underground Space for Urban Planning and Management-Providing Basic Planning Insight. University of Twente. 
Glander, T., Döllner, J., 2009. Abstract representations for interactive visualisation of virtual 3D city models. Comput. Environ. Urban Syst. 33(5), 375-387.

Gröger, G., Kolbe, T., Nagel, C., Häfele, K.-H., 2012. OGC City Geography Markup Language (CityGML) En-coding Standard. OGC. ogc.org/standards/citygml.

Kada, M., 2006. 3D Building Generalization Based on HalfSpace Modeling. Int. Arch. Photogramm. Remote Sens. Spat. Inf. Sci. 36(2), 58-64.

Kelly, T. J. Femiani, P. Wonka, N.J. Mitra, 2017. BigSUR: Large-scale Structured Urban Reconstruction. ACM Transactions on Graphics, Vol. 36, No. 6, Article 204.

Kolbe, T.H., 2009. Representing and exchanging 3D city models with CityGML, in: 3D Geo-Information Sciences. Springer, Berlin, Heidelberg, pp. 15-31.

Köninger, A., Bartel, S., 1998. 3D-GIS for Urban Purposes. Geoinformatica 2(1), 79-103.

Lieberman, J., Ryan, A., 2017. OGC Underground Infrastructure Concept Study Engineering Report. OGC Engineering Report. opengis.net/doc/PER/uicds.

MacEachren, A.M., 2004. How maps work: representation, visualisation, and design. Guilford Press.

Mao, B., Ban, Y., Harrie, L., 2011. A multiple representation data structure for dynamic visualisation of generalised 3D city models. ISPRS J. Photogramm. Remote Sens. 66(2), 198-208. doi.org/10.1016/j.isprsjprs.2010.08.001.

Mays, L.W., 2018. Water Distribution System Operation, in: Optimal Control of Hydrosystems. CRC Press, pp. 131-162.

Meng, L., Forberg, A., 2007. 3D Building Generalisation, in: Generalisation of Geographic Information. Elsevier, pp. 211231.

Schrotter, G., Van Son, R., 2018. Digital Underground- Towards a Reliable Map of Subsurface Utilities in Singapore. digitalunderground.sg/.

Stoter, J., Zlatanova, S., 2003. 3D GIS, where are we standing, in: ISPRS Joint Workshop on'Spatial, Temporal and MultiDimensional Data Modelling and Analysis. Québec, Canada.

Thiemann, F., 2002. Generalization of 3D Building Data. Int. Arch. Photogramm. Remote Sens. Spat. Inf. Sci. 34(4), 286-290.

Van Son, R., Jaw, S.W., Yan, J., Khoo, H.S.V., Loo, W.K.R., Teo, S.N.S., Schrotter, G., 2018. A framework for reliable threedimensional underground utility mapping for urban planning. Int. Arch. Photogramm. Remote Sens. Spat. Inf. Sci. - ISPRS Arch. 42, 209-214. doi.org/10.5194/isprs-archives-XLII-4-W10-2092018.

van Zyl, J., 2014. Introduction to Operation and Maintenance of Water Distribution Systems, Water Research Commision.

Vangenot, C., Parent, C., Spaccapietra, S., 2002. Modelling and Manipulating Multiple Representations of Spatial Data, in: Advances in Spatial Data Handling. Springer, Berlin, Heidelberg, pp. 81-93.
Wang, C., 2015. 3D Visualization of Cadastre: Assessing the Suitability of Visual Variables and Enhancement Techniques in the 3D Model of Condominium Property Units. Université Laval.

Wang, M., Deng, Y., Won, J., Cheng, J.C.P., 2019. Automation in Construction An integrated underground utility management and decision support based on BIM and GIS. Autom. Constr. 107, 102931 .

Yan, J., Jaw, S., Soon, K., Wieser, A., Schrotter, G., 2019. Towards an Underground Utilities 3D Data Model for Land Administration. Remote Sens. 11(17), 1957. doi.org/10.3390/rs11171957.

Zlatanova, Siyka, Abdul Rahman, A., Pilouk, M., 2002. Trends in 3D GIS Development. J. Geospatial Eng. 4(2), 71-80.

Zlatanova, Sisi, Rahman, A.A., Pilouk, M., 2002. 3D GIS : Current status and perspectives. Int. Arch. Photogramm. Remote Sens. Spat. Inf. Sci. 34(4), 66-71. 